\title{
Neuropsychological test performance in African-American* and white patients with Alzheimer's disease
}

\author{
K.A. Welsh, PhD; G. Fillenbaum, PhD; W. Wilkinson, PhD; A. Heyman, MD; \\ R.C. Mohs, PhD; Y. Stern, PhD; L. Harrell, MD, PhD; S.D. Edland, MS; and D. Beekly, BS
}

\begin{abstract}
Article abstract-Little information exists on the performance of black versus white patients with Alzheimer's disease on neuropsychological tests for dementia. In this study, we compared performance on the CERAD (Consortium to Establish a Registry for Alzheimer's Disease) neuropsychological battery between white $(n=830)$ and black $(n=158)$ patients with Alzheimer's disease enrolled in the CERAD study at 23 university medical centers in the United States. The black patients were older, had fewer years of formal education, and were more impaired in their activities of daily living than were the white patients. After controlling for these characteristics and for duration of the disease and severity of dementia, there were differences in the performance of black and white patients on several of the cognitive measures. Black patients scored lower than whites on tests of visual naming and constructional praxis and on the Mini-Mental State Examination. There were no statistical differences in performance on tests of fluency and word list memory. These findings suggest that cultural or experiential differences may modify performance on specific neuropsychological tests. These factors, in addition to age and educational background, should be considered when interpreting performance on neuropsychological tests in elderly black patients with dementia.
\end{abstract}

NEUROLOGY 1995;45:2207-2211

Studies of aging and Alzheimer's disease (AD) have shown that differences in educational and cultural experiences can affect performance on cognitive testing. ${ }^{1,2}$ Tests of intelligence, particularly tests based on general knowledge ${ }^{3}$ or naming ${ }^{4-6}$ and some tests of verbal learning and memory, are affected by these factors. ${ }^{7}$ Even nonverbal tests (eg, the Block Design subtest of the Wechsler Adult Intelligence Scale-Revised or tests of constructional praxis), often considered to be "culturally fair," are affected by cultural background, resulting in minority groups scoring less well on these measures than white comparison groups..$^{6,8-12}$

\footnotetext{
* Although the term "African-American" has been used recently to refer to black Americans in order to emphasize cultural roots and deemphasize race, the term "black" has been used by researchers and notable black scholars in the literature on minority aging. To avoid confusion and for purposes of consistency, we use the term "black" throughout the text to refer to the African-American group.
}

A major challenge in cross-cultural studies of dementia is distinguishing differences in groups based on (1) cultural or experiential differences, (2) the effects of age, education, and other modifying variables, and (3) biological differences in the illness per se. These alternatives are often difficult to evaluate because of a lack of information on the neuropsychological features of various dementias in different cultural, racial, and ethnic groups. This situation is changing, however, as the result of an increased interest in cross-cultural neuropsychological studies. ${ }^{13-16}$

In the present investigation, we examined the performance of black and white patients with $A D$ on tests frequently used to evaluate cognitive impairment caused by this disorder. By controlling for factors such as age, education, and duration and severity of dementia, this study specifically addresses the role of racial factors (eg, cultural or ex-

From the Duke University Medical Center (Drs. Welsh, Fillenbaum, Wilkinson, and Heyman), Durham, NC; the Mount Sinai School of Medicine (Dr. Mohs) and Columbia University (Dr. Stern), New York, NY; the University of Alabama-Birmingham (Dr. Harrell), Birmingham, AL; and the University of Washington (D. Beekly and S. Edland), Seattle, WA.

Supported by NIA AG06790 CERAD (Consortium to Establish a Registry for Alzheimer's Disease) study and AG05128 to the Bryan Alzheimer's Disease Research Center at Duke University Medical Center.

Presented in part at the annual meeting of the American Neurological Association, San Francisco, CA, October 1994.

Received November 28, 1994. Accepted in final form April 8, 1995.

Address correspondence and reprint requests to Dr. Kathleen Welsh, Bryan Alzheimer's Disease Research Center, Duke University Medical Center, 2200 West Main Street, Suite A-230, Durham, NC 27705. 
periential differences) on neuropsychological test performance in dementia. The results underscore the importance of having norms based on cultural background when interpreting neuropsychological test performance in elderly black or other minority subjects with dementia.

Methods. Subjects. The AD patient groups in this study consisted of 158 elderly blacks and 830 elderly whites recruited from 23 university medical centers participating in the Consortium to Establish a Registry for Alzheimer's Disease (CERAD). Each patient satisfied strict entry criteria that excluded serious neurologic, medical, and psychiatric disorders that could affect mentation. All subjects were English-speaking and were 50 years of age or older at entry into the study. Informed consent was obtained from each subject or from an appropriate caregiver by methods approved by the institutional review board at each center.

Clinical assessment. Each patient enrolled in this project was examined by a physician with expertise in dementia. The clinical assessment, described elsewhere, ${ }^{17}$ consisted of a semistructured interview to determine cognitive and functional status, a drug inventory, taking of depression and medical history, the six-item Short Blessed Test, ${ }^{18}$ and a general physical and neurologic examination. Diagnoses of either probable or possible $\mathrm{AD}$ were made based on a modification of the criteria of the NINCDS-ADRDA Work Group. ${ }^{19}$ The stage of severity of the dementia was quantified using the Clinical Dementia Rating scale ${ }^{20}$ (CDR) and the activities of daily living measures from the Blessed Dementia Rating Scale. ${ }^{21}$ Estimated duration of disease (in years) and scores from the Blessed Dementia Rating Scale and from the CDR were included in the analyses to control for severity and duration of illness.

Neuropsychological tests. The CERAD neuropsychological assessment battery was administered at each of the participating sites by trained, certified psychometricians whose ratings were independent of the physicians' clinical evaluations. This battery of tests was designed to assess the basic cognitive functions affected in $\mathrm{AD}$ and includes the following measures, presented in their order of administration:

1. Verbal fluency test (fluency). This test measures verbal production, semantic memory, and language. ${ }^{22}$ It requires the subject to name as many examples of animals as possible within 1 minute.

2. Boston Naming Test-modified (naming). This test is a measure of visual naming and presents 15 line drawings of common objects from the Boston Naming Test. ${ }^{28}$ These items are stratified into three groups of five items each, representing objects of high (easy to name), medium, and low (hard to name) frequency of occurrence in the English language. The maximum possible score is 15 .

3. Mini-Mental State Examination (MMSE). The CERAD version is a slight modification of this wellknown screen of cognitive function. ${ }^{24}$ It measures orientation, language, concentration, constructional praxis, and memory. The serial subtraction subtest is replaced by the alternative test procedure, ie, spelling "world" backwards. The maximum possible score on the test remains 30 .

4. Word list memory (word list learning). This is a free-recall memory test that is included in the Alzheimer's Disease Assessment Scale (ADAS) ${ }^{25}$ and assesses learning ability for new verbal information. Three trials of a 10-item word list are presented. On each trial, the 10 words are presented in a different order. The subject is instructed to read each word aloud as it is presented. Immediately after each trial, the subject is asked to recall as many words as possible. The maximum possible score on each trial is 10 . To reduce the number of variables analyzed, performance on each of the three trials was summed to provide a total learning score.

5. Constructional praxis (praxis), This task is also derived from the ADAS. ${ }^{25}$ It measures visuospatial and constructional abilities and requires the subject to copy four line drawings, presented in order of increasing complexity (circle, diamond, overlapping rectangles, cube). The total possible score is 11 .

6. Word list recall (delayed recall). This test assesses the subject's ability to recall, after a 5-minute delay, the 10 words given in the above-mentioned word list memory test. The maximum possible number of correct responses is 10. Savings scores were computed by comparing the amount of information recalled on the delayed trial to the number recalled on the last (third) learning trial of the word list.

7. Word list recognition. The remaining test assesses recognition of the words shown in the word list memory task when presented among 10 distractor words, with a maximum possible score of 10 for correct recognition of the targets and a maximum score of 10 for correct discrimination of distractors.

Three of the neuropsychological test measures were excluded from further consideration in the analyses due to extreme floor/ceiling effects in both AD groups (delayed recall, word list recognition) or because of substantial correlation with other measures (savings scores dropped; correlation with word list learning: $r=0.93$ ).

Statistical procedures. Descriptive statistics (means, standard deviations, and percentages as appropriate) were computed for the two groups on the demographic variables, on disease-related measures, and on each of the five cognitive measures; multivariate analysis of variance was used to compare the cognitive measures between the two groups. Because age, sex, education, duration of illness, and degree of functional impairment (as measured by the Blessed Dementia Rating Scale and CDR scores) are possible correlates of the cognitive measures, these covariates were examined as potential effect modifiers and confounders of the relationship between race and performance on the five remaining neuropsychological measures (fluency, naming, MMSE, word list learning, and praxis). For example, if the effect of race on MMSE score were to be different for males and females, then sex would "modify" the effect of race on MMSE score and would be considered an effect modifier. On the other hand, an apparent relationship between race and MMSE score might be due to the association of each with a third variable, such as education. In this latter example, education would be considered a confounder of the relationship between race and MMSE score.

The examination of effect modifiers was accomplished by testing the significance of statistical interactions between an indicator variable for race and the six covariates (ie, age, sex, education, estimated duration of illness, Blessed Dementia Rating Scale score, and CDR score) in multivariate regression models; each model included the indicator variable for race and all six covariates in addition to the interaction of interest. These multivariate tests revealed that none of the six interactions was statistically significant.

The examination of potential confounders of the effect 
of race on the cognitive measures was accomplished by comparing the coefficient of the indicator variable for race in a regression model that contained all six covariates with the coefficient of the indicator variable in "reduced" models in which one or more covariates were omitted. Any covariate that could not be omitted without causing a meaningful change in the race coefficient was included in the final model as a confounder (without regard to the statistical significance of the coefficient). Of the six covariates, only sex could be removed from the model without causing a meaningful change in the race coefficient for at least one of the five neuropsychological measures. Thus, age, years of education, estimated duration of illness, Blessed Dementia Rating Scale score, and CDR score were all included in the final model, a multivariate analysis of covariance, which was used to evaluate the relationship of race to the five neuropsychological measures.

Post hoc univariate comparisons of the five neuropsychological measures and $95 \%$ confidence intervals for the effect of race, adjusted for the effects of the five covariates, were based on the multivariable regression models. All statistical analyses were carried out using SAS (SAS, version 6.04, SAS Institute, Cary, NC, 1991).

Results. Table 1 shows that the black subjects were older than the whites, had fewer years of formal schooling, and had somewhat more severe dementia. Although both the black and the white patient groups included more women than men (as

Table 1. Demographic and disease characteristics of 830 white patients and 158 black patients with Alzheimer's disease

\begin{tabular}{|lrrrrr|}
\hline & \multicolumn{3}{c}{ White } & & \multicolumn{2}{c|}{ Black } \\
\cline { 2 - 3 } \cline { 5 - 6 } Characteristic & Mean & SD & & Mean & SD \\
Age & 71.8 & 8.0 & & 74.0 & 7.8 \\
Male (\%) & 43.5 & - & & 26.6 & - \\
Education (yr) & 12.6 & 3.5 & & 10.6 & 4.2 \\
Duration of disease (yr) & 4.4 & 2.7 & & 3.5 & 2.4 \\
BDRS score & 4.5 & 2.5 & & 5.1 & 2.7 \\
CDR score & 1.5 & 0.6 & & 1.6 & 0.7 \\
BDRS Blessed Dementia Rating Scale. & & & & \\
CDR Clinical Dementia Rating scale. & & & & \\
\hline
\end{tabular}

expected in a study of $\mathrm{AD}$ ), there were proportionally fewer black men than white men ( $27 \%$ versus $44 \%$ ). However, gender did not appear to be a confounder, as it did not affect the race coefficient for any of the neuropsychological measures, as stated previously. Estimated duration of illness was somewhat less in the black patients despite the more severe symptoms reported.

Table 2 shows the scores on the five neuropsychological measures for black and for white patients. Given the differences in age, education, and severity of dementia between the two groups, the neuropsychological scores of the black patients were lower (as might be expected) than those of the white patients $(\mathrm{F}[5,982]=19.43, p<0.001)$.

Age, education, estimated duration of disease, and severity of illness were controlled in all subsequent analyses in an effort to explore the effects of other racial factors (table 2, adjusted means). Analysis of outcomes on the five neuropsychological measures (naming, word list learning, praxis, MMSE, and fluency), adjusted for the effects of the five covariates, indicated a highly significant difference for race $(F[5,977]=12.99, p<0.001)$. Although black patients tended to perform worse than whites on all nearly measures, univariate comparisons revealed statistically significant differences between the two racial groups for only three measures: naming $(t=7.21, p<0.001)$, MMSE ( $t=2.59, p<0.01)$, and constructional praxis $(t=2.72, p<0.01)$.

Discussion. Our findings indicated that black patients with $\mathrm{AD}$ performed worse than white patients on several of the CERAD neuropsychological measures. These differences persisted even after controlling for confounding characteristics, such as differences in age, education, estimated duration of disease, and severity of dementia, but performance was not equally affected on all the neuropsychological tests. Black patients performed significantly worse than whites on the MMSE, on the constructional praxis test, and particularly on the naming of line drawings. These findings are consistent with reported observations ${ }^{26}$ of lower scores on the

Table 2. Neuropsychological test scores of 830 white patients and 158 black patients with Alzheimer's disease

\begin{tabular}{|c|c|c|c|c|c|c|}
\hline \multirow[b]{2}{*}{ Test } & \multirow{2}{*}{$\frac{\text { White }}{\text { Mean (SD) }}$} & \multirow{2}{*}{$\frac{\text { Black }}{\text { Mean (SD) }}$} & \multicolumn{4}{|c|}{ Adjusted means* } \\
\hline & & & White & Black & Difference & $95 \% \mathrm{CI}$ \\
\hline Naming & 10.78 & $8.12(3.44)$ & 10.67 & 8.69 & 1.98 & $(1.44,2.52)$ \\
\hline Word list learning & $7.41(4.55)$ & $6.89(4.76)$ & 7.33 & 7.34 & -0.01 & $(-0.71,0.69)$ \\
\hline Praxis & $7.07(2.82)$ & $5.87(2.92)$ & 6.97 & 6.37 & 0.60 & $(0.17,1.03)$ \\
\hline MMSE & $17.68(5.60)$ & $15.63(6.57)$ & 17.52 & 16.48 & 1.04 & $(0.25,1.83)$ \\
\hline Fluency & $7.67(4.26)$ & $6.68(3.98)$ & 7.58 & 7.20 & 0.38 & $(-0.29,1.05)$ \\
\hline $\begin{aligned} * & \text { Mean scores } \\
& \text { Blessed Dem } \\
\text { CI } & \text { Confidence ir } \\
\text { MMSE } & \text { Mini-Mental }\end{aligned}$ & $\begin{array}{l}\text { d for the effects } \\
\text { ting Scale and by } \\
\text { amination. }\end{array}$ & $\begin{array}{l}\text { covariates: age, } \\
\text { nical Dementia }\end{array}$ & $\begin{array}{l}\text { n, durati } \\
\text { cale. }\end{array}$ & ease, an & ease severity & asured by the \\
\hline
\end{tabular}


Boston Naming Test in normal elderly black subjects compared with age-matched white controls. Our findings are also consistent with those obtained in epidemiologic studies and community surveys ${ }^{27-29}$ that showed that the MMSE and similar cognitive screening measures resulted in high false-positive rates for dementia in blacks. Conversely, other reports ${ }^{30,31}$ suggest that education, not racial group per se, significantly affects MMSE scores in normal elderly persons. This discrepancy between clinical and epidemiologic studies may be due to other differences in the samples, such as socioeconomic status, which is known to affect MMSE scores. ${ }^{32}$

Of note is our finding that the score on the memory measure (word list learning) was approximately the same in the black and the white subjects. This finding is in contrast to the results of a study ${ }^{7}$ in a somewhat younger sample of randomly selected black, Hispanic, and white community residents on a 20-item word list memory test. In that study, with age, sex, and education controlled, elderly black subjects showed significantly worse performance on list learning and delayed recall. These findings suggest that $\mathrm{AD}$ may be a "race leveler" on learning and memory measures, so that any preexisting differences between groups on these measures are outweighed by the dementing process. The disease may result in a complete or nearly complete loss of recent memory function, thereby negating any previous advantages conferred by cultural or experiential background.

Our earlier studies showed that delayed recall and savings scores are highly sensitive to the early stages of $\mathrm{AD}^{33,34}$ but are relatively unaffected by age, education, and gender. ${ }^{35}$ The findings on these two measures were not included in this investigation for reasons discussed earlier. Because these measures were highly intercorrelated with the word list learning procedures, ${ }^{17}$ we expect that there would not be race differences on delayed memory and savings scores. If these findings are confirmed by others, then tests of learning and memory may be particularly important measures to include in future cross-cultural studies of aging and dementia. Since these cognitive measures are not as affected by racial factors, performance on the learning and memory measures may permit less ambiguous diagnosis of cognitive impairment in diverse cultural groups.

A caveat is necessary in interpreting the findings reported here. Our study groups consisted entirely of patients with a diagnosis of AD. Since cerebrovascular disease is often present clinically and at autopsy in elderly black patients with dementia, ${ }^{36-38}$ some of the differences between the racial groups in this study may possibly reflect the effects of comorbid cerebrovascular disease. This possibility is highly unlikely, however, because all the patients with $\mathrm{AD}$ in this CERAD study had extensive medical evaluation, including neuroimaging studies, to exclude the possibility of major cere- brovascular disease. We are looking at the effects of vascular risk factors (eg, hypertension) and less severe cerebrovascular disease in our continuing studies.

Regardless of cause, the finding of a significant difference in cognitive function in the two racial groups (even after adjusting for education, age, and other characteristics) is noteworthy. These observations, along with the growing evidence from similar reports, ${ }^{6,7,39}$ strongly suggest the need for normative information in minority groups. This is an important point to keep in mind when evaluating patients from minority or other cultural groups. There may be differences in educational experiences across groups that are not completely controlled for through statistical covariance or by applying white educational norms. Specifically, the quality of education may not be captured by simply adjusting for years of education. Additionally, clinicians should be aware that cultural differences in the reporting of disease symptoms may also be operating across groups, leading to differences in the reported symptoms as well as in the estimates of disease duration. ${ }^{40}$ For example, a higher tolerance for the cognitive effects of aging in one group could lead to later medical attention for the dementia and result in the appearance of more severe symptoms over a shorter duration of disease. Studies are needed on the possible role of these various sociocultural differences, health characteristics, and other demographic factors (such as socioeconomic status) on the natural history of $\mathrm{AD}$ in black and white patients and on the reporting of disease symptoms. ${ }^{40,41}$

\section{Acknowledgments}

We would like to acknowledge the various CERAD centers and the many investigators (neurologists, psychiatrists, neuropsychologists, and clinical coordinators) at each site who contributed the patient data to this work. The centers include Burke Rehabilitation Center, White Plains, NY; Baylor University College of Medicine, Houston, TX; Case Western Reserve University, Cleveland, OH; Columbia University, New York, NY; Duke University Medical Center, Durham, NC; Emory University School of Medicine, Atlanta, GA; The Graduate Hospital, Philadelphia, PA; Johns Hopkins University, Baltimore, MD; Massachusetts General Hospital, Boston, MA; Mount Sinai Medical Center, New York, NY; University of Alabama, Birmingham, AL; University of Kentucky Medical Center, Lexington, KY; University of Pittsburgh Medical School, Pittsburgh, PA; University of Rochester Medical Center, Rochester, NY; University of Southern California, Los Angeles, CA; University of Texas Southwestern Medical Center, Dallas, TX; University of Washington, Seattle, WA; Veterans Administration Medical Center and University of California at San Diego, La Jolla, CA; Veterans Administration Medical Center, Minneapolis, MN; and Washington University School of Medicine, St. Louis, MO.

\section{References}

1. Stern Y, Gurland B, Tatemichi TK, et al. Influence of education and occupation on the incidence of Alzheimer's disease. JAMA 1994;271:1004-1010.

2. Zhang M, Katzman R, Salmon D, et al. The prevalence of de- 
mentia and Alzheimer's disease in Shanghai, China: impact of age, gender, and education. Ann Neurol 1990;27:428-437.

3. Anastasi A. Psychological testing. 6th ed. New York: MacMillan Press, 1988.

4. Borod JC, Goodglass H, Kaplan E. Normative data on the Boston Diagnostic Aphasia Examination, Parietal Lobe Battery, and the Boston Naming Test. J Clin Neuropsychol 1980;2:209-215.

5. Rosselli M, Ardila A, Florez A, Castro C. Normative data on the Boston Diagnostic Aphasia Examination in a Spanishspeaking population. J Clin Exp Neuropsychol 1990;12:313322.

6. Loewenstein DA, Arguelles T, Barker WW, Duara R. A comparative analysis of neuropsychological test performance of Spanish-speaking and English-speaking patients with Alzheimer's disease. J Gerontol 1993;48:P142-P149.

7. Fillenbaum GG, Burchett BM, Welsh KA. The 20-item word list test as a measure of cognitive functioning in the Health and Retirement Survey: norms and validity for white, African-American, and Hispanic respondents. Health and Retirement Study Working Paper Series: paper \#94-005. Ann Arbor, MI: University of Michigan Survey Research Center, 1994.

8. West PA, Hill SY, Robins LN. The Canter Background Interference Procedure (BIP): effects of demographic variables on diagnosis. J Clin Psychol 1977;33:765-771.

9. Overall JE, Levin HS. Correcting for cultural factors in evaluating intellectual deficit on the WAIS. J Clin Psychol 1978;34:910-915.

10. Penk WE, Brown AS, Roberts WR, et al. Visual memory of black and white male heroin and nonheroin drug users. J Abnorm Psychol 1981;90:486-489.

11. Adams RL, Boake C, Crain C. Bias in a neuropsychological test classification related to education, age, and ethnicity. $J$ Consult Clin Psychol 1982;50:143-145.

12. Kaufman AS, McLean JE, Reynolds CR. Analysis of WAIS-R factor patterns by sex and race. J Clin Psychol 1991;47: 548-557.

13. Judd T, DeBoard R. The state of the art in cross-cultural neuropsychology II. Clinical practice [abstract]. J Clin Exp Neuropsychol 1993;15:18-19.

14. Ponton MO, Herrera $\mathrm{L}$. The state of the art in cross-cultural neuropsychology I: salient issues [abstract]. J Clin Exp Neuropsychol 1993;15:18.

15. Puente AE. Ethics in neuropsychology: a cross-cultural perspective [abstract]. J Clin Exp Neuropsychol 1993;15:19.

16. Loewenstein DA, Arguelles T, Arguelles S, Linn-Fuentes P. Potential cultural bias in the neuropsychological assessment of the older adult. J Clin Exp Neuropsychol 1994;16:623-629.

17. Morris JC, Heyman A, Mohs RC, et al. The Consortium to Establish a Registry for Alzheimer's Disease (CERAD). Part I. Clinical and neuropsychological assessment of Alzheimer's disease. Neurology 1989;39:1159-1165.

18. Katzman R, Brown T, Fuld P, Peck A, Schechter R, Schimmel $H$. Validation of a short orientation-memory-concentration test of cognitive impairment. Am J Psychiatry 1983; 140:734-739.

19. McKhann G, Drachman D, Folstein M, Katzman R, Price D, Stadlan EM. Clinical diagnosis of Alzheimer's disease: report of the NINCDS-ADRDA Work Group under the auspices of Department of Health and Human Services Task Force on Alzheimer's Disease. Neurology 1984;34:939-944.

20. Hughes CP, Berg L, Danziger WL, et al. A new clinical scale for the staging of dementia. Br J Psychiatry 1982;140:566572 .

21. Blessed $G$, Tomlinson $E$, Roth $M$. The association between quantitative measures of dementia and of senile change in the cerebral grey matter of elderly subjects. Br J Psychol 1968;114:797-811.

22. Rosen WG. Verbal fluency in aging and dementia. J Clin Neuropsychol 1980;2:135-146.

23. Kaplan EF, Goodglass H, Weintraub S. The Boston naming test. Philadelphia: Lea \& Febiger, 1983.

24. Folstein MF, Folstein SE, McHugh PR. 'Mini-mental state.' A practical method for grading the cognitive state of patients for the clinician. J Psychiatr Res 1975;12:189-198.

25. Rosen WG, Mohs RC, Davis KL. A new rating scale for Alzheimer's disease. Am J Psychiatry 1984;141:1356-1364

26. Lichtenberg PA, Ross T, Christensen B. Preliminary normative data on the Boston Naming Test for an older urban population. Clin Neuropsychol 1994;8:109-111.

27. Anthony JC, LeResche L, Niaz U, et al. Limits of the 'MiniMental State' as a screening test for dementia and delirium among hospital patients. Psychol Med 1982;12:397-408.

28. Fillenbaum G, Heyman A, Williams $K$, et al. Sensitivity and specificity of standardized screens of cognitive impairment and dementia among elderly black and white community residents. J Clin Epidemiol 1990;43:651-660.

29. George LK, Landerman R, Blazer DG, et al. Organic mental disorders and cognitive impairment. In: Robins LN, Regier DA, eds. Psychiatric disorders in America. New York: Free Press, 1991:291-327.

30. Fillenbaum GG, Hughes DC, Heyman A, et al. Relationship of health and demographic characteristics to Mini-Mental State Examination score among community residents. Psychol Med 1988;18:719-726.

31. Murden RA, McRae TD, Kaner S, Bucknam ME. Mini-mental state exam scores vary with education in blacks and whites. J Am Geriatr Soc 1991;39:149-155.

32. Brayne $\mathrm{C}$, Calloway $\mathrm{P}$. The association of education and socioeconomic status with the Mini Mental State Examination and the clinical diagnosis of dementia in elderly people. Age Ageing 1990;19:91-96.

33. Welsh KA, Butters N, Hughes J, et al. Detection of abnormal memory in mild cases of Alzheimer's disease using CERAD neuropsychological measures. Arch Neurol 1991;48: 278-281.

34. Welsh KA, Butters N, Hughes JP, et al. Detection and staging of dementia in Alzheimer's disease: use of the neuropsychological measures developed for the Consortium to Establish a Registry for Alzheimer's Disease. Arch Neurol 1992; 49:448-452.

35. Welsh KA, Butters N, Mohs RC, et al. The Consortium to Establish a Registry for Alzheimer's Disease (CERAD). Part V. A normative study of the neuropsychological battery. Neurology 1994;44:609-614.

36. Folstein M, Anthony JC, Parhad I, et al. The meaning of cognitive impairment in the elderly. J Am Geriatr Soc 1985; 33:228-235

37. de la Monte SM, Hutchins GM, Moore GW. Racial differences in the etiology of dementia and frequency of Alzheimer lesions in the brain. J Natl Med Assoc 1989;81:644-652.

38. Heyman A, Fillenbaum G, Prosnitz B, et al. Estimated prevalence of dementia among elderly black and white community residents. Arch Neurol 1991;48:594-598.

39. Inouye SK, Albert MS, Mohs R, et al. Cognitive performance in a high-functioning community-dwelling elderly population. J Gerontol 1993;48:M146-M151.

40. Welsh KA, Ballard E, Nash F, Raiford K, Harrell L. Issues affecting minority participation in studies of Alzheimer disease. Alzheimer Dis Assoc Disord 1994;8:38-48.

41. Helms JE. Why is there no study of cultural equivalence in standardized cognitive ability testing? Am Psychol 1992;9: 1083-1101. 